\title{
CHANGES IN FRACTAL DIMENSION OF PHRAGMITES AUSTRALIS LEAVES UNDER CHRONIC RADIATION EXPOSURE*
}

\author{
D. Ganzha1, Ch. Ganzha ${ }^{2 * *}$ \\ ${ }^{1}$ Ivano-Frankivsk Department of the Ukrainian Geographical Society \\ 2Institute of Hydrobiology of NAS of Ukraine
}

\begin{abstract}
We analyzed the fractal dimension of the common reed leaves collected in the Chornobyl exclusion zone in conditions of chronic radiation exposure. On a macroscopic level, the fractal dimension was calculated for images of leaves taken from an optical scanner. On a microscopic level, it was calculated for images obtained from a scanning electronic microscope at $100 \times$ and $500 \times$ magnification. Statistical analysis showed the dependence of fractal numbers on morphological parameters of leaves on macroscopic and microscopic levels. We found a direct correlation of the fractal dimension of the images to the content of phosphorus and nitrogen compounds in water reservoirs, and a regenerative connection with internal exposure doses, depending on the physical and chemical forms of radionuclides incorporated in the leaves. The results showed the prospect of the application of the fractal analysis of the leaves as an integral figure in the diagnosis of environmental quality.
\end{abstract}

Key words: Biology indication, common reed, radioecology, plant anatomy and morphology

\section{INTRODUCTION}

An important integral method in bioindication is the measurement of the fractal geometry of leaves and their venation in the first place, since this feature is one of the most important characteristics of higher plants that have evolutionary, systematic and ecological significance [1]. In modern science, to describe biological objects that have fractal properties, such as scale invariance or self-similarity, the language of fractal geometry is used [2]. The fractal dimension of plant leaves is not only a speciesspecific phenomenon, but it also has intraspecific differences such as the varieties of cultivated plants [3]. It can also be used to assess the environmental quality in terms of man-made pollution. For example, under the influence of chronic radiation exposure, common reed forms leaves with fractal dimension that is different from that of the uncontaminated ecosystems [4]. However, the lack of reliable methods for estimating the uncertainty in measurements prevents the use of the fractal dimension of leaves for the evaluation of environmental quality in the conditions of radiation contamination. It is known that the inevitable morphological variability and inaccurate manifestation of repeating units is characteristic of biological quasi-fractals [2]. Thus, to adapt the method of fractal dimension analysis of plant leaves and to diagnose the environmental quality, it is necessary to solve the problem of setting the main morphological traits affecting the fractal dimension of leaves, assess their relationship with environmental parameters, optimize the procedure of calculating the fractal dimension, and estimate the statistical uncertainty measurements.
The aim of our study was to evaluate the correlation of the fractal dimension of common reed leaves with their morphological parameters, changes in terms of different levels of radiation exposure and provision of the plant with mineral elements.

\section{MATERIALS AND METHODS}

Leaves of Phragmites australis (Cav.) Trin. ex Steud (common reed) were sampled in June 2011 in the ecosystems of six water bodies of the Chornobyl Exclusion Zone: lake Azbuchyn, lake Glyboke, lake Daleke, Yaniv backwater of Prypiat river near the town of Prypiat, cooling pond of Chornobyl Nuclear Power Plant (Nuclear Power Plant basin), and Prypiat river transit near the city of Chornobyl (Chornobyl transit). During the vegetation period of 2012, water samples were selected from the same water bodies. Samples of common reed leaves from the Chornobyl transit were considered to be taken in the conditions of regional background radiation contamination. To compare with the regional background of noncontaminated areas (Ukrainian Polissya zone), common reed leaves were selected in the ecosystem of the lake Pisochne (Shatsky Lakes).

30 to 50 leaves of common reed were selected at each observation site. The samples were cooled to $5^{\circ} \mathrm{C}$ and delivered in a cooler bag from the selection sites to the laboratory.

Under laboratory conditions, three mid-sized leaves were selected from each sample for electronic microscopy. Other leaves were scanned and then sent for the analysis of the contents of physical-chemical forms of radionuclides.

Vegetation samples were divided into six fractions. Extraction was conducted in the following

\footnotetext{
"The paper was presented at the Fourth International Conference on Radiation and Applications in Various Fields of Research (RAD 2016), Niš, Serbia, 2016.

${ }^{* *}$ krisdgan@gmail.com
} 
sequence: 1) dissolved extracellular cations (DEC) using distilled $\mathrm{H}_{2} \mathrm{O}$; 2) adsorbed extracellular loosely coupled cations (AELC) - using $\mathrm{NiCl}_{2}$ solution; 3) adsorbed extracellular cations (AEC) - using EDTA solution; 4) intracellular cations (InC) - using $\mathrm{HNO}_{3}$ solution (1 M); 5) cations associated with organic matter $(\mathrm{COM})-$ using $35 \% \mathrm{H}_{2} \mathrm{O}_{2}+\mathrm{HNO}_{3}$ solution; 6) mineral residue (MR) - marginally soluble residue decomposition using concentrated $\mathrm{HCl}$ solution $[5,6$, 7].

Specific activity of ${ }^{90} \mathrm{Sr}$ and ${ }^{137} \mathrm{Cs}$ in components were determined by radiochemical analysis [8, 9]. ${ }^{137} \mathrm{Cs}$ content was determined on a SBS-30 gamma-ray spectrometer based on germanium-lithium detector ("Green Star Company", Russia), efficiency factor for ${ }^{137} \mathrm{Cs}$ is $1 \%$, separative power for energy is $3-4 \mathrm{keV}$, and for ${ }^{60} \mathrm{Co}$ it is $1333 \mathrm{keV}$.

${ }^{90} \mathrm{Sr}$ was leached using $\mathrm{HCl} \mathrm{1:1} \mathrm{solution,} \mathrm{activity}$ measurement was conducted using a ${ }^{\circ 0} \mathrm{Y}$ daughter product on UMF-200o ("Doza", Russia), a low background facility based on siliceous ion-implanted detector [8]. During measuring operations, expanded uncertainty limit did not exceed $15 \%$.

Based on the measurement results, according to the existing recommendations [10], the dose rate of internal radiation of common reed leaves was calculated.

The selected water samples were stored frozen until the analysis. In the samples, using the method of electrochemical analysis and an ion meter pX-150MI (Russia) with ion-selective electrodes, ion content was determined for $(\mathrm{mg} / \mathrm{L}) \mathrm{Ca}^{2+}, \mathrm{Cl}^{-}, \mathrm{K}^{+}, \mathrm{Mg}^{2+}, \mathrm{NH}_{4}{ }^{+}$, $\mathrm{NO}_{2}{ }^{-}, \mathrm{NO}_{3}{ }^{-}, \mathrm{S}^{2-}$. Mass concentration $(\mathrm{mg} / \mathrm{L})$ of phosphate ions $\left(\mathrm{P}^{-}\right)$and iron was determined by using photocolorimetric methods and KPhK-2 photocolorimeter (Russia). The chemical absorption of oxygen in water samples $(\mathrm{mg} / \mathrm{L})$ was determined titrimetrically. Conductivity (Cond, $\mathrm{mS} / \mathrm{cm}$ ) and $\mathrm{pH}$ of water samples were determined using a quality analyzer U-10 (Horiba, Japan). Mass concentration of suspended materials and solid residue was determined by the gravimetric method $(\mathrm{mg} / \mathrm{L})$.

Maximum permissible statistical error in the analysis of radionuclides did not exceed $20 \%$, while in hydro-chemical analysis it was $5 \%$.

Minimal abnormal excess of the background hydrochemical parameters in water was calculated by the formula [12]:

$$
C_{A}=X_{\Phi} \cdot \mathcal{E}
$$

where $\varepsilon=\operatorname{antlg} \sigma_{l g}$ is the standard multiplier, $\sigma_{l g}$ is the standard deviation of logarithms of test parameter values.

The total pollution water index $(\mathrm{Zc})$ was calculated by the formula [13]:

$$
\mathrm{Z}_{C}=\sum_{i=1}^{n} K_{C}-(n-1)
$$

where $n$ is the number of recorded abnormal water parameters; $K C$ is the concentration factor calculated as the ratio of the concentration of a substance in a sample to its background content; $K_{C I}$ is average value for all calculated $K_{C}$.
For the microscopic analysis, freshly sampled leaves of common reed were used. The thickness of the central vein $(d c, \mathrm{~mm})$ and the second-order veins $(d v, \mathrm{~mm})$ was measured using a digital caliper. Leaves in the second quartile of the place of attachment to the stem were scanned from adaxial side of transmitted light at $600 \mathrm{dpi}$.

For the micro-morphological analysis, we used the incisions of air-dried leaves in the center of the leaf along the midrib. Images of the leaf surface were made by the scanning electronic microscope $100 \mathrm{U}$ SEM with $100^{\times}$and $500^{\times}$magnification. The shooting took place on the adaxial side of the leaves [4].

Raster black and white (1-bit) images (macro- and microphotography of leaves surface) were subjected to fractal analysis using software ImageJ, version $1.45 \mathrm{~s}$. The calculation of the fractal dimension of $D$ was performed by 12, 16, 32, 64, 128, 256, 512, 1024, 2048 regions of increasing size necessary for inscribing the image in them. The calculated value of $D$ was taken as a measure of the pattern regularity (self-similarity) of individual lamina in the leaves. For each observation site, we calculated the average value of the coefficient of variation of the number $D$ of all the common reed leaves analyzed by images.

For the statistical analysis of the relations of the fractal dimension of the leaf laminas image with morphometric parameters, we used the following data from our previously conducted researches [13]: thickness of collateral conduction bundles $\left(d_{C B}, \mu \mathrm{m}\right)$, density of stomata coating lamina $\left(P_{p}, \mathrm{n} / \mathrm{MM}^{2}\right)$. We also used index curvature of collateral conduction bundles $(K k)$. This ratio was calculated by the formula [Ibid]:

$$
K_{\kappa}=\left(l_{n}-l_{\kappa}\right) / l_{\kappa},
$$

where: $l_{C B}$ is per unit (linear) length of the conduction bundles in the micro-image; $l_{s}$ is the shortest distance between the outermost points of the image of conduction bundles.

The total uncertainty of measurement $(u)$ was calculated in accordance with the recommendations [14] by the formula:

$$
u(\%)=\sum_{c} u_{c}(\%)
$$

where: $u_{c}$ is composing uncertainty of measurement. In this case, we take into account only the factors affecting the random uncertainty components: $u_{c}(\%)=V(\%)=s \cdot \bar{x}^{-1} \cdot 100$, where $V(\%)$ is the coefficient of variation; $s$ is the experimental sample's standard deviation, and $\bar{x}$ is the sample mean.

\section{RESULTS AND DISCUSSION}

3.1. Selection of the optimal number of regions of the pattern partition and evaluation of the uncertainty measurement of fractal numbers

According to the results of the 1960 measurements of leaves surface fractal numbers on 280 macrographs and 90 measurements on 18 
micrographs revealed that the maximum number of results (37\%) in the analysis of macrographs lay in the region of the partition of the images into 32 box sizes (Fig. 1). When analyzing micrographs, the maximum number of results (62\%) lay in the range of 1024 box sizes.

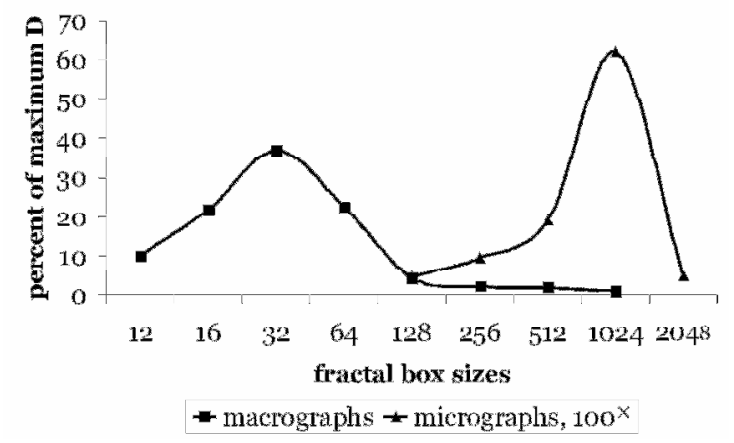

Figure 1. Distribution of 2048 fractal numbers in various images of box sizes

The fact that the groups of pictures lie in different areas of box sizes is obviously connected with the resolution of macrographs which is $600 \mathrm{dpi}$ and micrographs - 72dpi. Changes in the number of $D$ for different scales of shooting are due to the morphological and anatomical structure of the leaves' conductive tissue, shown with a corresponding increase. Thus, scanning a 1:1 image with the resolution of 600 dpi with a minimum amount of $0.04 \times 0.04 \mathrm{~mm}$, veins of the third order are visible (Fig. 2).

Since the main elementary structural components of the patterns at all scales of shooting are line features - veins or collateral conduction bundles, the maximum value of fractal numbers is respectively associated with the formed fractal pattern.

On the images of micropreparations, along with the linear elements of conductive bundles, stomata participate in creating fractal patterns (Fig. 3, 4). In this case, the micrograph shows not the actual stoma but wax coatings that cover them.

At multiplicity of the micrograph, the role of stomata in the formation of a fractal pattern increases, which leads to a natural increase in the number of $D$ for all studied box sizes (Fig. 5). A disproportionate increase has been observed in the number of fractal images in a box size data of 2048 at $500^{\times}$magnification. This is due to the violation of wax lumps on certain preparations related to the stomata and due to the occurrence of areas with "placers" of small objects in areas where stomata are located on the images. Large values of standard deviations, observed in the analysis of micrographs, arose because of small sampling. Therefore, those are the evaluation data. Slight differences in the numbers of fractal dimension $\left(n \cdot 10^{-3}\right)$, resulting from the calculation of 512 and 1024 box sizes, allow the use of average numbers received from them for subsequent calculations and the consequent assumption that this average value describes the results with $80 \%$ reliability (Fig. 1).

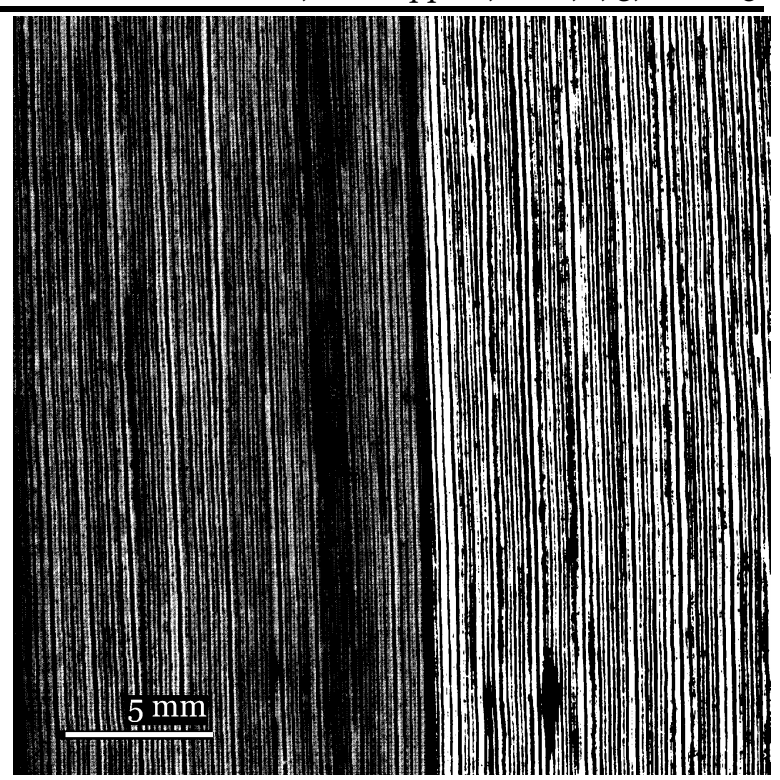

Figure 2. Fragment of a common reed leaf from the lake Pisochne. The right side of the image was taken after linearization in black and white format. Veins of the second and third order are clearly visible. (Scale 1:1, $600 \mathrm{dpi}$ )

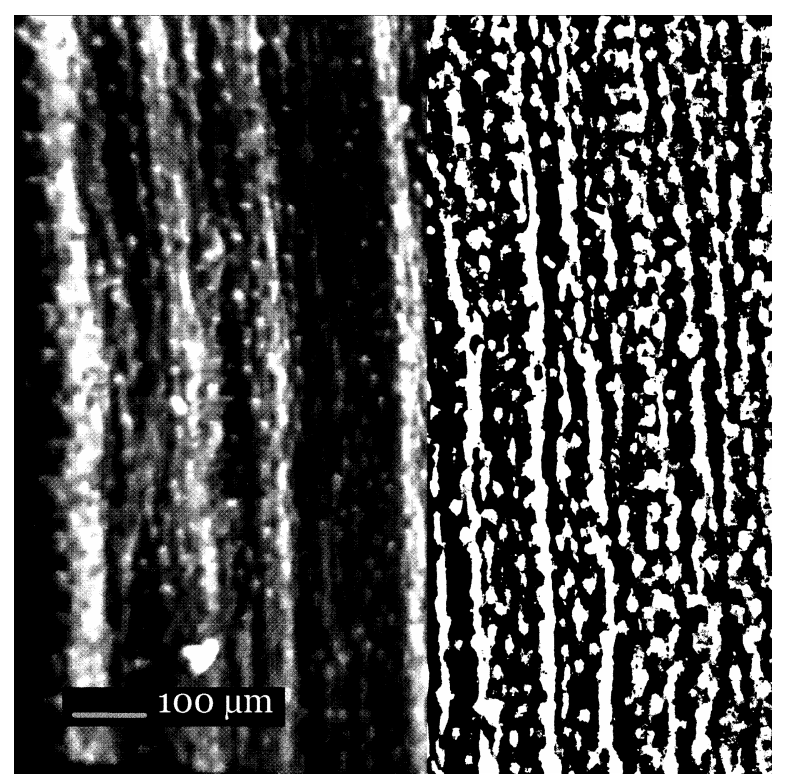

Figure 3. Fragment of a common reed leaf from the lake Pisochne. The right side of the image was taken after linearization in black and white format (100× magnification) 
D. Ganzha, Ch. Ganzha, Changes in Fractal Dimension..., Rad. Applic., 2016, 1, 3, 210-215

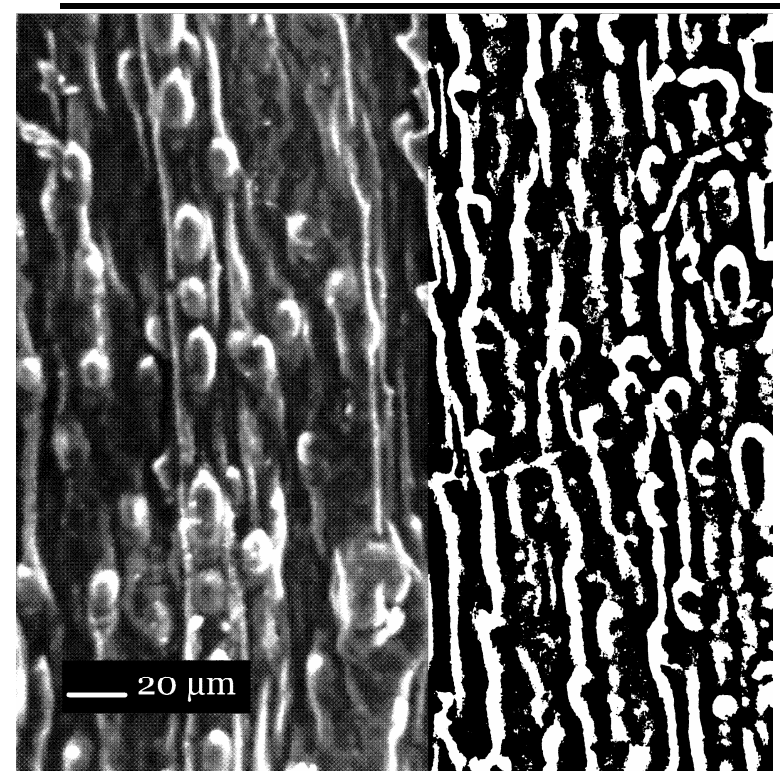

Figure 4. Fragment of a common reed leaf from the lake Pisochne. The right side of the image was taken after linearization in black and white format. $\left(500^{\times}\right.$ magnification)

The analysis of fractal dimension of macrographs revealed that the largest peaks in the number of $D$ were obtained by partitioning the images into 32 boxes (Fig. 1). Analyzing fractal dimension peaks on the images partitioned into 12 and more, 64 box sizes were predominantly observed in the leaves infected by necrosis and chlorosis, with a poorly expressed surface across the picture, or in some places with a pattern of venation, etc. The highest values of standard deviation are also characteristic of these data samples. The lowest levels of standard deviation fall on the box sizes of 32 and 64 (Fig. 6). Standard deviation of the fractal dimension obtained in partitioning into 32 boxes covers the values obtained from the box sizes of 16 and 64 . This ratio of standard deviation and values of $D$ allows the use of the average value of fractal dimension obtained by box sizes of 16 , 32 and 64.

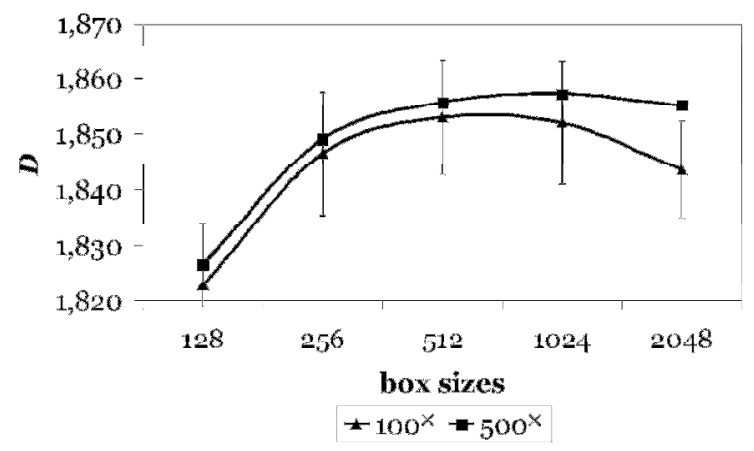

Figure 5. Fractal dimension of micrographs depending on box sizes

The statistical uncertainty of number $D$ measurements on macrographs was calculated as the sum of the values of $u$, calculated according to Formula 4, and the proportion of these samples
(19\%), which accounts for the value of $D$ obtained in box sizes of 12 and more than 64 (Fig. 1, Table 1).

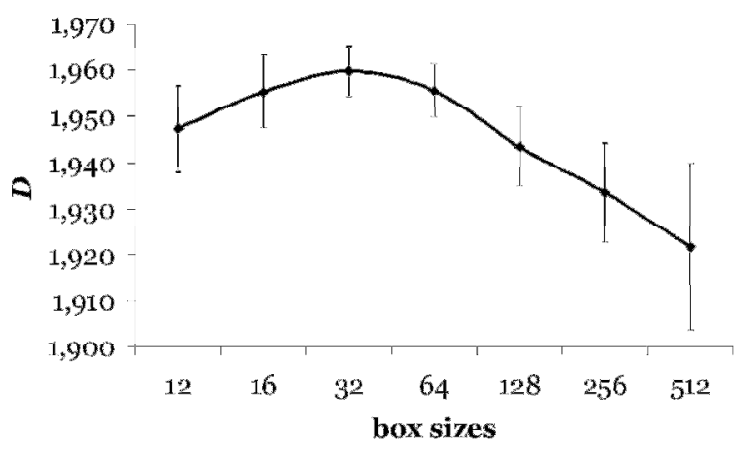

Figure 6. Fractal dimension of macrographs depending on box sizes on the example of leaves from the ecosystem of Chornobyl transit, Prypiat river

Table 1. Fractal dimension of images of common reed leaves

\begin{tabular}{|cccccc|}
\hline $\begin{array}{c}\text { Surveillance } \\
\text { places }\end{array}$ & $n$ & $\begin{array}{c}D, \\
\text { macro }\end{array}$ & $\begin{array}{c}u, \\
\%\end{array}$ & $\begin{array}{c}D, \\
\text { micro } \\
100^{\times}\end{array}$ & $\begin{array}{c}D, \\
\text { micro } \\
500^{\times}\end{array}$ \\
Azbuchyn Lake & 33 & 1.9465 & 22 & 1.8623 & 1.8698 \\
NPP pool & 36 & 1.9586 & 20 & 1.8623 & 1.8450 \\
Glyboke Lake & 40 & 1.9507 & 21 & - & - \\
$\begin{array}{c}\text { Daleke Lake } \\
\text { Chornobyl } \\
\text { transit }\end{array}$ & 30 & 1.9532 & 20 & 1.852 & 1.861 \\
Yaniv backwater & 40 & 1.9575 & 20 & 1.8456 & 1.8590 \\
Pisochne Lake & 49 & 1.9518 & 20 & - & - \\
\hline
\end{tabular}

3.2. Relation of fractal dimension of the images of common reed leaves to their morphological parameters

When common reed is exposed to chronic internal radiation and influenced by chemical substance contamination of water bodies, a morphological response of leaves on the macroscopic and microscopic level occurs. The relative amount and irregularity of stomata on the leaf arrangement increase, thickness and curvature of collateral vascular bundles and the veins of the 2nd and 3 rd order reduce, and the distance between them increases. Changes in the morphometric parameters of the leaves occur with varying intensity, depending on the competitive action of absorbed chemical substances and radionuclides, as well as depending on plant tissue reaction to the radiation absorbed dose [13]. The fractal dimension of leaf images can be considered an integral indicator of the morphological changes of the leaf blades.

Regression-correlation analysis of the relation of the fractal dimension of common reed leaves showed an average and tight relation, in some cases a reverse connection, to the morphological parameters of the leaves (Table 2). 
Table 2. Relation of anatomical and morphological parameters of common reed leaves with the fractal dimension

\begin{tabular}{|c|c|c|c|c|c|}
\hline \multirow{2}{*}{$\begin{array}{c}\text { Leaf } \\
\text { para- } \\
\text { meters }\end{array}$} & \multirow{2}{*}{$\begin{array}{c}\text { Morpho- } \\
\text { metric } \\
\text { data }\end{array}$} & \multirow[b]{2}{*}{$\begin{array}{l}\mathrm{V}, \\
\%\end{array}$} & \multicolumn{3}{|c|}{$\begin{array}{c}\text { Determination coefficient, } \\
\mathrm{R}^{2}\end{array}$} \\
\hline & & & $\begin{array}{c}D, \\
\text { macro }\end{array}$ & $\begin{array}{c}D, \\
\text { micro } \\
100^{\times}\end{array}$ & $\begin{array}{c}D, \\
\text { micro } \\
500^{\times}\end{array}$ \\
\hline$d_{C}$ & $\begin{array}{l}0.24 \\
\mathrm{~mm}\end{array}$ & 17 & 0.61 & $\begin{array}{c}0.76 \\
(-)\end{array}$ & $\begin{array}{c}0.30 \\
(-)\end{array}$ \\
\hline$d_{V}$ & $0.13 \mathrm{~mm}$ & 23 & 0.87 & $\begin{array}{c}0.72 \\
(-)\end{array}$ & 0.58 \\
\hline$d_{C B}$ & $5 \mu \mathrm{m}$ & 10 & 0.34 & $\begin{array}{c}0.30 \\
(-)\end{array}$ & - \\
\hline$P_{p}$ & 90 & 36 & 0.49 & $\begin{array}{c}0.50 \\
(-)\end{array}$ & $\begin{array}{c}0.38 \\
(-)\end{array}$ \\
\hline$K_{\kappa}$ & 4.7 & 60 & 0.48 & $\begin{array}{c}0.30 \\
(-)\end{array}$ & - \\
\hline
\end{tabular}

Note: the value of the determination coefficient was calculated at safety level $P=0.95$; "-" - no data; "(-)" - data form the inverse relationship.

The essence of the damaging effect lies in thinning, rectification of conduction bundles, and in an increase of the specific number of stomata [13]. At the same time, macromorphological parameters of the leaves vary slightly.

Relation of the fractal dimension of macrographs with micro-morphological parameters, such as the thickness of the conduction bundles $\left(d_{C B}\right)$, density of the stomata coating $\left(P_{p}\right)$ and curvature coefficient of conduction bundles $\left(K_{\kappa}\right)$, is apparently mediated. We also found the reverse relation of the thickness of the central vein $\left(d_{C}\right)$ and second-order veins $\left(d_{V}\right)$ with the fractal dimension of micrographs of the leaves. The reverse nature of the correlation of the fractal dimension of micrographs with the morphological parameters of the leaves is due to the specificity of reaction of the leaves to a chronic radiation exposure, due to which radiation effects occur primarily at the micro-level, and at the macro-level they are shown only in the doses maximum to the region.

\subsection{Relation of the fractal dimension of the images to the dose of radiation exposure of common reed leaves and hydro-chemical indicators of water bodies}

Of the fourteen hydro-chemical indicators, for which tests of water samples were carried out, the correlation of fractal numbers of images of leaves was detected for five chemicals and for the total index of water pollution $\left(Z_{c}\right)$ calculated from the measurements of all ingredients. We detected the following concentration parameters of hydrochemical indicators relevant to this study: potassium $-4.5 \mathrm{mg} / \mathrm{L}$, at $\mathrm{V}-41 \%$; calcium - $520 \mathrm{mg} / \mathrm{L}$, at $\mathrm{V}$ 130\%; nitrite nitrogen - $0.10 \mathrm{mg} / \mathrm{L}$, at V - 65\%; phosphates - $0.70 \mathrm{mg} / \mathrm{L}$, at V - 46\%;

The specific activity of ${ }^{137} \mathrm{Cs}$ in the common reed leaves, selected in CEZ, ranged from $120 \mathrm{~Bq} / \mathrm{kg}$ dry weight in the samples from the Chornobyl alignment of Pripyat river to $27000 \mathrm{~Bq} / \mathrm{kg}$ in the samples from the Glyboke lake. Specific activity of ${ }^{\circ} \mathrm{Sr}$ in the leaves changed from $80 \mathrm{~Bq} / \mathrm{kg}$ to $7900 \mathrm{~Bq} / \mathrm{kg}$, respectively. The average in-site dose of ${ }^{137 \mathrm{Cs}}$ is $0.39 \mu \mathrm{Gy} / \mathrm{h}$, at V $110 \%$; ${ }^{90} \mathrm{Sr}-0.14 \mu \mathrm{Gy} / \mathrm{h}$, at $\mathrm{V}-120 \%$. The ratio of intracellular cations and those embedded in the tissue of common reed leaves is $30 \%$ and $60 \%$ for ${ }^{137 \mathrm{Cs} \text {, and }}$ $5 \%$ and $86 \%$ for ${ }^{\circ} \mathrm{Sr}$, respectively. From six physicalchemical forms of radionuclides measured in the leaves, ${ }^{137} \mathrm{Cs}$ is less related to the fractal dimension and ${ }^{\circ} \mathrm{Sr}$ is more related to it (Table 3 ).

Table 3. Relation of hydrochemical parameters of water bodies to the internal radiation dose of the fractal dimension of common reed leaves

\begin{tabular}{|c|c|c|c|c|}
\hline \multirow[b]{2}{*}{ Object } & \multirow[b]{2}{*}{ Parameter } & \multicolumn{3}{|c|}{ Determination coefficient, $\mathrm{R}^{2}$} \\
\hline & & $D$, macro & $\begin{array}{c}D, \text { micro } \\
100^{\times}\end{array}$ & $\begin{array}{c}D, \text { micro } \\
500^{\times}\end{array}$ \\
\hline \multirow{6}{*}{ Water } & $\mathrm{Ca}^{2+}$ & 0.31 & o & $\mathrm{O}$ \\
\hline & $\mathrm{K}^{+}$ & 0.45 & o & $0.32(-)$ \\
\hline & $\mathrm{NO}_{2}^{-}$ & 0.50 & o & $0.49(-)$ \\
\hline & $\mathrm{P}^{3-}$ & 0.76 & o & $0.59(-)$ \\
\hline & Cond & 0.43 & O & $0.35(-)$ \\
\hline & $Z_{c}$ & $0.37^{*}$ & o & $0.53(-)$ \\
\hline \multirow{8}{*}{ Leaves } & 137Cs (Sum) & $0.50^{*}(-)$ & o & o \\
\hline & ${ }^{137} \mathrm{Cs}(\mathrm{InC})$ & $0.42^{*}(-)$ & $0.62^{*}$ & 0.40 \\
\hline & ${ }^{137} \mathrm{Cs}(\mathrm{COM})$ & $0.43^{*}(-)$ & o & $\mathrm{O}$ \\
\hline & ${ }^{90} \mathrm{Sr}$ (Sum) & $0.57^{*}(-)$ & O & 0 \\
\hline & ${ }^{90} \mathrm{Sr}(\mathrm{DEC})$ & $0.79(-)$ & o & o \\
\hline & ${ }^{90} \mathrm{Sr}$ (AELC) & o & $0.44(-)$ & O \\
\hline & ${ }^{90} \mathrm{Sr}(\mathrm{InC})$ & $0.27^{*}(-)$ & O & O \\
\hline & ${ }^{90} \mathrm{Sr}(\mathrm{COM})$ & $0.59^{*}(-)$ & $\mathrm{O}$ & 0.48 \\
\hline
\end{tabular}

Note: this table lists only the parameters that show correlation with the fractal dimension, the value of the determination coefficient was calculated at safety level $P=0.95$; "'o" indicates the lack of correlation; "(-)" - data from the inverse relationship, "*" shows logarithmic cases, others are linear cases; (AELC, COM, DEC, InC, Sum) - see explanation of radionuclides fractions in vegetation samples in the section Materials and Methods.

The reliable correlation relationship of studied anatomical and morphological parameters of the leaves with external doses and root system radiation exposure doses were not discovered [13]. In this study, the reliable correlation relationship of the external exposure of all plants of common reed to incorporated radionuclides with the fractal dimension of leaf images was not found.

Most available correlations are described by linear regression, except for formed radionuclides. Table 3 shows a competitive relationship between $\mathrm{Ca}$ and $\mathrm{K}$ cations with ${ }^{90} \mathrm{Sr}$ and ${ }^{137} \mathrm{Cs}$ on the example of a different nature of correlations with the fractal dimension of macrographs of the leaves ( $D$, macro), a direct relation with macro-elements and a regressive relation - with radionuclides. It can be seen that the mineral food elements in the water plants contribute to the increase of fractal numbers, i.e. they increase the level of self-similarity of fractal patterns of venation in the leaves, while the increasing dose of internal exposure has the opposite effect. The radionuclides incorporated within cells ( $\mathrm{InC}$ ) and those embedded in the structure of plant tissue 
(COM) are the most effective in this case. The correlation of fractal number micrographs with $100^{\times}$ magnification can hardly be seen. This is obviously due to the fact that their fractal pattern is formed by the impact of competitive patterns of conduction bundles and stomata.

The results showed that the fractal dimension of the common reed leaves is mostly determined by their anatomical and morphological structure. It is proved by the developed correlations of hydrochemical indicators and dosimetric cost on one side and fractal dimensions of micrographs $(500 \times)$ on the other side. In this case, a stomatal apparatus plays an important role in the creation of a fractal pattern. As mentioned above, the data in the Table 3 confirm that chronic radiation exposure leads to an increase of the specific number of stomata on common reed leaves [13]. This case also shows that the dose increase augments the number of fractal patterns made by the stomata. This process is opposite to what happens with venation, but perhaps similar to conduction bundles.

\section{CONCLUSIONS}

The fractal dimension of common reed leaves is determined by their anatomical and morphological structure.

Both chronic exposure from incorporated radionuclides and saturation of the ecosystem with elements of mineral nutrition of plants impact the fractal dimension of common reed leaves. Meanwhile, the change of morphological parameters of the leaves also depends on anthropogenic environmental factors. In the observation conditions, radionuclides incorporated within the cells and associated with organic matter exert the greatest influence on the fractal dimension of leaves. The impact of ${ }^{90} \mathrm{Sr}$ causes

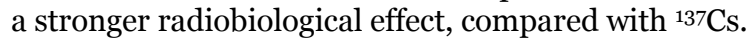

It has been determined that fractal dimensions of the images of leaves vary depending on the number of regions required for inscribing in the image, which leads to the necessity of preliminary image analysis to identify morphological elements forming the fractal pattern.

The method of analysis of the fractal dimension of leaves can be used to assess the environmental quality in the conditions of technogenesis, particularly in radionuclide contamination of water ecosystems.

Acknowledgements: The authors would like to thank the manager of Freshwater Radiology Department of the Institute of Hydrobiology of NAS of Ukraine, Senior Scientist D.I. Gudkov, Doctor of
Biological Sciences for his support in conducting these observations.

\section{REFERENCES}

1. A. L. Takhtajan, Fundamentals of evolutionary morphology of angiosperms, Moscow-Leningrad, Soviet Union: Nauka, 1964, p. 236.

2. V. V. Isaeva, Y. A. Karetin, A. V. Chernyshev and D. Y. Shkuratov, Fractals and Chaos in biological morphogenesis, Vladivostok, Russia: Dal'nauka, 2004 , p. 128.

3. N. I. Fedoryaka, PhD Dissertation, Michurinsk, Russia, 2004.

4. D. D. Ganzha, A. B. Nazarov, V. B. Rybalka and G. I. Petelin, "Changes veining common reed leaves under the influence of incorporated radionuclides," Proc. of IV int. Conf. on Radioactivity and radioactive elements in human environment, Tomsk, Russia, 2013, pp. 139-142.

5. M. D. Vazquez, J. Lopez and A. Carballeira, "Uptake of Heavy Metals to the Extracellular and Intracellular Compartments in Three Species of Aquatic Bryophyte," Ecotoxicology and Environmental Safety, vol. 44, no. 1, pp. 12 - 24, 1999.

6. D. H. Brown and J. M. Wells, "Physiological effects of heavy metals on the moss Rhytidiadelphus squarrosus," Ann. Bot., vol. 66, no. 6, pp. 641-647, 1990.

7. A. Bolsunovsky, T. Zotina and L. Bondareva, "Accumulation and release of ${ }^{241} \mathrm{Am}$ by a macrophytes of the Yenisei River (Elodea canadensis)", Journal of Environmental Radioactivity, vol. 81, no. 1, pp. 3346, 2005.

8. A. K. Lavrukhina T. V. Malyshev and F. I. Pavlotskaya, Radiochemical Analysis, Moscow, Soviet Union: USSR Academy of Sciences, 1963, p. 220.

9. A. Y. Golfman and L. Z. Kalmykov, "Determination of radioactive cesium ferrocyanide way," Radiochemistry, vol. 4, no. 10, pp. 107-109, 1963.

10. Handbook for assessment of the exposure of biota to ionising radiation from radionuclides in the environment, J. Brown, P. Strand, Al. Hosseini, P Børretzen Eds., Project within the EC 5th Framework Programme, Contract No FIGE-CT-2000-00102. Framework for Assessment of Environmental Impact, 2003.

11. A. P. Solovov et al., Handbook of geochemical mineral exploration, Nedra, Moscow, Russia, 1990.

12. Y. E. Saet, et al., Geochemistry Environment, Moscow, Russia: Nedra, 1990.

13. D. D. Ganzha and A. B. Nazarov, "Influence of chronic exposure to radiation on a nervation and location of mouth-like opening in the leaves of Phragmites australis (Cav.) Trin. ex Steud, Bulletin of Lviv University," Biology Series, vol. 69, pp. 119-128, 2015.

14. Joint Committee for Guides in Metrology. (Sep. 2008) Evaluation of measurement data - Guide to the express ion of uncertainty in measurement. 